\title{
INVESTIGACIÓN/RESEARCH
}

\section{INGENIERÍA DE LA METONIMIA EN LA PUBLICIDAD GRÁFICA}

\author{
Marian Núñez-Cansado ${ }^{1}$ : Universidad de Valladolid. España \\ Mariannc11@yahoo.es
}

\section{RESUMEN}

Este artículo es fruto de una investigación realizada con el objetivo de analizar el rol de la metonimia cognitiva en la creatividad publicitaria. En él se analiza el proceso metonímico como elemento clave en la creación de significados y como componente indispensable en las estrategias publicitarias, para lo cual la se utilizaron diversos métodos teóricos como es: el análisis documental y el lógico-histórico. Entre lo resultados más sobresaliente subrayar El grado de retórica más representativo de los anuncios donde se han encontrado este tipo de metonimia, es el grado 4, es decir, existe una representación bastante significativa del resto de los grupos de recursos, de hecho no existe ningún anuncio donde la metonimia de construcción constituya un nivel 1 de retórica.

PALABRAS CLAVE: Retórica, Creatividad, Metonimia, Psicología Cognitiva, Publicidad

\section{METONYMY ENGINEERING IN GRAPHICS ADVERTISING}

\begin{abstract}
Cognitive Engineering of metonymy in display advertising is the result of an investigation in order to analyze the role of metonymy in cognitive advertising creativity. Metonymic process is analyzed as a key element in the creation of meaning and as an indispensable component in advertising strategies. Is used various theoretical methods such as: document analysis and logical-historical. The main results were: the level of rhetoric more representative of the ads is the grade 4 . There is a very significant representation on the group. There is no announcement of metonymy rhetoric Level 1.
\end{abstract}

\footnotetext{
${ }^{1}$ Autor correspondiente

Marian Núñez-Cansado. Profesora y Doctora de la Universidad de Valladolid, España.

Correo: Mariannc11@yahoo.es
} 
KEY WORDS: Rhetoric, Creativity, Metonymy, Cognitive Psychology, Advertising

\section{INTRODUCCIÓN}

\subsection{Metonimia: el singular desplazamiento de significado}

La sustitución metonímica se basa en la relación de inclusión o contigüidad que se origina entre los elementos, lo que implica que, contrariamente a la metaforización, en la metonimia puede llegarse a respetar la presencia de los dos términos en cuestión, manteniendo los límites figurativos de cada uno de ellos, en una secuencia de tiempo o espacio.

Cuando tiene lugar esta sustitución se produce un desplazamiento de significado de un término a otro, se trata de un desplazamiento que se establece en una sola dirección, no se produce entre los términos una identificación o una doble dirección, como sucede en los procesos metafóricos.

Esta doble dirección convierte a la metáfora en un recurso con grandes posibilidades de combinación entre los distintos conceptos, contrariamente al caso del proceso metonímico, ya que éstos deben siempre partir de entidades relacionadas con el concepto original, convirtiendo la relación en real, no artificial.

A cambio, este tipo de relación metonímica no obliga al receptor a ejercitar una actividad tan creativa como en el caso de la metáfora, recurso en el que es necesario un gran salto imaginativo para interpretar el mensaje. Así, cuando los términos comparten el campo semántico, el sujeto se beneficia de una fácil reconstrucción de una historia desde la exposición de una pequeña parte.

Umberto Eco:

la metonimia está basada en la contigüidad entre el objeto representado y el detalle del mismo que representa al conjunto total, por lo que no requiere de la transposición que presupone el salto imaginativo que la metáfora requiere. Está diferencia puede llevar a la metonimia a ser interpretada como más "natural" que la metáfora, que actúa según similitud².

En los procesos metafóricos, la relación entre los términos tiene lugar en un plano paradigmático, lo que implica por necesidad la utilización de términos que pertenecen a campos semánticos distintos. La relación sintagmática, entre los elementos que conforman la metonimia, es defendida por los experiencialistas Lakoff y Johnson ${ }^{3}$, que parten de la definición del proceso metonímico como un proceso basado en el apareamiento dentro de un mismo dominio.

\footnotetext{
2 Umberto Eco. Tratado de Semiótica General. Editorial Lumen, Colección Palabra en el Tiempo. 1975. Quinta Edición 2000,

${ }^{3}$ Lakoff,G. y Johnson M. Metáforas de la vida cotidiana, Madrid: Cátedra (2001)
} 
En el caso de la metáfora, el apareamiento se produce entre dos dominios conceptuales distintos, la relación entre ambos dominios está presidida por la sustitución, donde un dominio es entendido en términos del otro.

En la metonimia no sucede así, puesto que se parte de un solo dominio conceptual, no existe la transferencia del dominio de origen al dominio meta, ya que la estructura de ambos lados del apareamiento es la misma, lo que propicia un deslizamiento en el dominio y no entre dominios, deslizamiento que según Roman Jakobson modifica al referente sin que parezca alterarse la significación.

\section{2 Objetivos de investigación}

Analizar el rol de la metonimia desde la perspectiva cognitiva en la comunicación publicitaria. Cuáles son sus principales funciones y el papel que juega tanto en la construcción de significados como en la estrategia comunicacional de la marca.

Establecer clasificaciones que nos permitan conocer mejor el funcionamiento del proceso metonímico en la creatividad impresa.

\section{METODOLOGÍA}

\subsection{Resultados cuantitativos}

Se llevó a cabo un análisis textual sobre un corpus de 851 anuncios $^{4}$, extraídos de 44 revistas, estimando un universo total de 573.593 anuncios. El universo total de anuncios se ha estimado partiendo de la siguiente fórmula: $\mathbf{U t}=\mathbf{5 7 3 . 5 9 3 2}$

La selección de las revistas de las que se extrajeron los anuncios se realizó de forma aleatoria teniendo en cuenta los siguientes criterios:

a) Revistas publicadas en lengua castellana

b) Revistas publicadas entre los años 1991 y 2001

Los anuncios han sido seleccionados según la clasificación de cuatro diferentes categorías que varían sustancialmente en sus contenidos y extensión. La selección de las categorías de los anuncios se ha realizado siguiendo el siguiente criterio:

1.- Categoría A: Bebidas: cualquier bebida promocionada, bien sea las

\footnotetext{
4 Anexo 1

${ }^{5} \mathrm{Ut}=\mathrm{T} \times \mathrm{N} \times \mathrm{P}$. Ut; universo total

T: total de años, en los que las revistas han sido seleccionadas. Desde el año 1991 hasta el año 2001. Con un valor de $\mathrm{T}=12\left(\sum\right.$ na $\left.=12\right)$

$\mathrm{N}$ : número de anuncios de cada revista

P: La periodicidad de emisión de la revistas, siendo el valor 1; para las revistas de tirada anual/ 52; para las revistas de tirada semanal (365 días / $7=$

52 semanas al año)/ 24; para las revistas de tirada quincenal (365 días / $15=24$ quincenas al año)/12; para las revistas de tirada mensual. / 2; para las revistas de tirada semestral
} 
denominadas alcohólicas, las alimenticias o los refrescos ${ }^{6}$

2.- Categoría B: Automóviles: en esta categoría encuadramos a todo tipo de vehículos, turismos, industriales de cuatro ruedas ${ }^{7}$

3.- Categoría C: Confección Textil: todo tipo de artículos relacionados con el atuendo femenino y masculino: vestidos, camisas, bolsos, zapatos ${ }^{8}$.

4.- Categoría D: Perfumería, Droguería, Cosmética Farmacéutica: tampones y compresas, perfumes y colonias, maquillajes, cosmética para el cuidado de la piel y la higiene personal y limpieza del hogar ${ }^{9}$

El corpus fue analizado en base a dos variables:

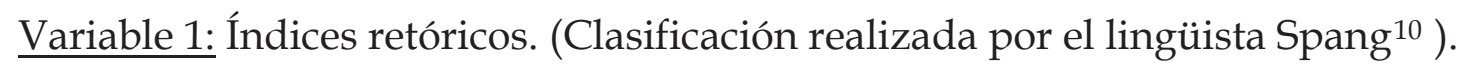

Variable 2: Índice de nivel retórico. Esta variable nos indicará el nivel retórico en los anuncios, estableciendo como partida la clasificación mostrada en la Variable 1. Así decimos que un anuncio de nivel 1 contiene al menos un recurso de un bloque, un anuncio de nivel 2 contiene recursos retóricos de dos bloques, y así sucesivamente hasta llegar al nivel 6.

Tras someter al corpus a la variable recursos retóricos, podemos afirmar que la presencia de la metonimia dentro del grupo de tropos es significativamente superior, superada tan sólo por la metáfora. Del total de 851 anuncios analizados, 734 utilizaban tropos como recursos persuasivos y del total de 734 anuncios, 396 utilizaban la metonimia como recurso principal(Ver Tabla 1).

Tabla 1. Distribución de criterios respecto a la Metonimia

\begin{tabular}{|l|l|}
\hline Metáfora & 581 \\
\hline Metonimia & 396 \\
\hline Atenuación & 3 \\
\hline Eufemismo & 51 \\
\hline Hipérbole & 239 \\
\hline Ironía & 27 \\
\hline Perífrasis & 36 \\
\hline Personificación & 39 \\
\hline Onomatopeya & 3 \\
\hline Sinestesia & 18 \\
\hline
\end{tabular}

\footnotetext{
${ }^{6}$ Categorías Bebidas: 259 anuncios

7 Categoría Automóviles: 188 anuncios

8 Categoría textil: 102 anuncios

${ }^{9}$ Categoría Perfumería Droguería: 302 anuncios

10 Spang, K.
} 


\section{ANÁLISIS Y DISCUSIÓN}

\subsection{La estructura de la metonimia en la publicidad gráfica}

La metonimia aporta todo un mundo de posibilidades a la comunicación publicitaria. Si la fotografía es definida por Dumarsais como la "génesis por metonimia"11, la publicidad pudiera ser definida como la metonimia por excelencia, donde todos y cada uno de sus elementos son entidades representativas de dominios conceptuales, comenzando por los escenarios, pasando por los protagonistas, y acabando por la marca y el producto.

La esencia misma de la publicidad está envuelta en un proceso metonímico, gracias al cual exhibimos un pequeño fragmento del mundo de forma seductora, la reconstrucción e interpretación de la realidad se deja en manos del sujeto receptor.

La publicidad reproduce los estereotipos sociales, cuyo comportamiento o aspecto físico, concuerda perfectamente con las exigencias del producto $\mathrm{y}$, consecuentemente, con los objetivos de comunicación, estimulando gracias a las neuronas espejo, mecanismos de identificación en los sujetos receptores que propician un acercamiento entre producto y consumidor. Esta identificación entre el sujeto receptor y el protagonista se convierte en una necesidad patente cubierta gracias a la capacidad de la metonimia de recrear patrones globales, de un dominio concreto, reconocido en la población.

Existen mecanismos cognitivos útiles para afrontar secuencias recurrentes de estas acciones básicas, estos mecanismos participan en el almacenamiento de información relativa a situaciones estereotipadas, patrones globales, eventos generalizados. El hombre se sirve de estos patrones para reconocer e interpretar una información nueva, para generar significados partiendo de entidades parcialmente representadas. Así, los significados se construyen a partir de intentos de comprender la realidad.

Las representaciones mentales filtran y dan forma a la percepción además de ayudar a procesar, comprender y organizar la información nueva

El sujeto trata de descifrar el significado del mensaje y para ello compara la información nueva con sus esquemas o estructuras cognitivas preexistentes, de modo que el mensaje se construirá en base a los conocimientos previos.

A menudo es necesario adaptar los esquemas de esta información para llevar a cabo la creación de significados, este es el caso más común en la publicidad. Patrones globales implantados en la sociedad son adaptados y acoplados a productos, de modo que las marcas terminan recibiendo el peso de las connotaciones inmersas en la sociedad y

${ }^{11}$ Du Marsais: Traité des Tropes, t.I, 4. (Tratado de los tropos, traducción de José Miguel Aléa (2 vols.), Madrid, Aznar) 
recreadas por la publicidad.

Alguno de los elementos más utilizados en la publicidad tiene su origen en procesos metonímicos como es el caso del logotipo, la reproducción de estereotipos, la recreación espacio temporal...

Así, el logotipo se convierte, mediante la educación visual, en parte del concepto semántico de la marca y a partir de este dominio conceptual se establecen distintas entidades capaces de representar de forma eficaz a la marca o al producto. La utilización de estos elementos es una práctica común en los anuncios y a este tipo de metonimia la definiremos como metonimia lexicalizada.

Las metonimias lexicalizadas como el logotipo, han sido obviadas en esta investigación con el fin de evitar distorsiones en el resultado final que pudiera conducirnos a una ponderación excesiva de las metonimias en su totalidad.

Serán consideradas en el análisis sólo aquellas metonimias que se establezcan fuera de estas prácticas generales, definidas en este estudio como metonimias semilexicalizadas.

\subsubsection{Reestructuración de los esquemas cognitivos}

Las metonimias semilexicalizadas que encontramos en la publicidad son reconstruidas con facilidad por el receptor, su capacidad de representación, propia de los procesos metonímicos, va a aportar a la comunicación publicitaria elementos imprescindibles para referenciar sus mensajes.

Frente a la metáfora, las inferencias ocasionadas por la metonimia están dotadas de una mayor precisión y menor ambigüedad, puesto que el desplazamiento referencial dado contextualmente, permite que los efectos denotativos estén ligados directamente a la intención del hablante y no al pensamiento creativo del receptor.

Creamos una serie de patrones globales que utilizamos para evaluar dominios conceptuales. Construimos campos semánticos sobre los que volcamos toda una serie de pareceres y prejuicios ya preconcebidos, juicios que pueden partir de la sociedad o de grupos más reducidos. Los patrones más utilizados en la publicidad son aquellos que son reconocidos por la sociedad en general o por alguna "tribu" en particular.

Gracias a estos patrones, el creativo puede activar la generación de significados de forma rápida y sin exigir gran esfuerzo al receptor, propiciando una mayor fluidez de procesamiento y con ello, un menor coste de aprendizaje y de memorización.

Esta aplicación retórica responde más que a una función referencial, que no descartamos en ningún momento, a una función puramente persuasiva. La presentación del producto o de la marca en uno $\mathrm{u}$ otro ambiente, responde a la necesidad de generar nuevos significados, forzando la reinvención o la adaptación de 
los esquemas cognitivos preexistentes, de los que a partir de ese momento formarán parte los productos o las marcas.

El origen de esta generación de significados es la asociación que se produce entre el esquema cognitivo y el producto. La mujer presentando un plato de pastas mientras platica en italiano. Se trata de la presentación de una pasta en un entorno italianizado, y es esta italianización la base persuasiva del anuncio. Partiendo de esta asociación producto/lugar, el sujeto receptor reconstruye sus esquemas incluyendo la marca y generando una nueva información. Existe un deslizamiento de significados, gracias al cual los atributos han sufrido un corrimiento de un concepto a otro, sin que ninguno de ellos pierda su significado como ocurría en la metáfora.

Encontramos en los anuncios analizados distintos niveles de densidad referencial contextualizada que permite al creativo generar inferencias en las que las ventajas preexistentes en los esquemas cognitivos se transfieren a los productos o marcas hasta tal punto que el esquema termina estando, en muchos casos, reinterpretado según las transferencias generadas desde la publicidad

Pongamos un ejemplo de ello: el color es uno de los elementos básicos en las estructuras de una marca. Aprendemos durante algún tiempo la asociación entre color y marca: azul/Telefónica, verde/Amena... Si preguntamos entre un grupo qué les sugiere el color rojo, podemos encontrar respuestas como: sangre, pasión, amor... Sin embargo si referenciamos la asociación automovilismo, la respuesta sin duda será Ferrari, si fuera bebida sería Coca - Cola, y si lo hiciéramos con telefonía sería Vodafone.

De esta forma, reestructuramos nuestros esquemas en base a la información que conocemos y que percibimos, en base al aprendizaje.

\subsubsection{Economía expresiva}

La metonimia es uno de los recursos retóricos con mayor capacidad para afrontar de forma eficaz la reducción formal en el nivel discursivo. Este proceso retórico permite un máximo nivel de precisión con una gran redundancia significativa: tan sólo la exposición a un fragmento de un marco cognitivo permite inferenciar todo su contenido.

El significante y el significado están asociados por un nexo de contigüidad que permite al creativo establecer asociaciones respetando siempre la economía expresiva. Se trata de un elemento clave que aporta un dato esencial a la hora de configurar la imagen de marca mediante la creación de sentido basado en un desplazamiento de significados, donde se produce una transferencia de atributos de un signo a otro sin que ninguno de ellos pierda su significado, uno de ellos se enriquece del otro adquiriendo sus cualidades o atributos. Esta estrategia proporciona al creativo numerosas oportunidades para recrear escenarios, reproducir historias, representar 
valores... facilitando la concentración de significados, la concisión y rapidez que además favorecen una mayor fluidez de procesamiento.

\subsection{Clasificación de la metonimia en la publicidad gráfica}

Atendiendo a las distintas funciones de la metonimia en la publicidad gráfica hemos establecido tres grupos:
a) Metonimia de Identidad
b) Metonimia de Referencia espacio - tempora
c) Metonimia de Construcción

\subsubsection{Metonimia de identidad}

Son aquellas metonimias que se construyen a partir de una entidad del producto promocionado. En los anuncios donde se establecen este tipo de metonimias, el producto promocionado está presente sólo mediante alguna de las partes que lo componen, se trata de un proceso de metonimización del producto en sí. Son utilizadas para resaltar algún elemento concreto o algún detalle del producto que defina parte de sus ventajas.

Los sectores de bebidas y de automóviles son los reyes de este tipo de metonimia. Son muchos los anuncios de ambas categorías que optan por la aplicación de la metonimia de identidad como estrategia creativa, decantándose por presentar de forma estética al producto mediante un tapón, una chapa o un corcho.

Al utilizar este tipo de metonimias, el creativo busca una nueva forma de presentar al producto, dando lugar a anuncios creativos e innovadores que contribuyen a mejorar su estética y que despiertan una llamada de atención en el receptor, rompiendo con la distracción que provoca la saturación publicitaria.
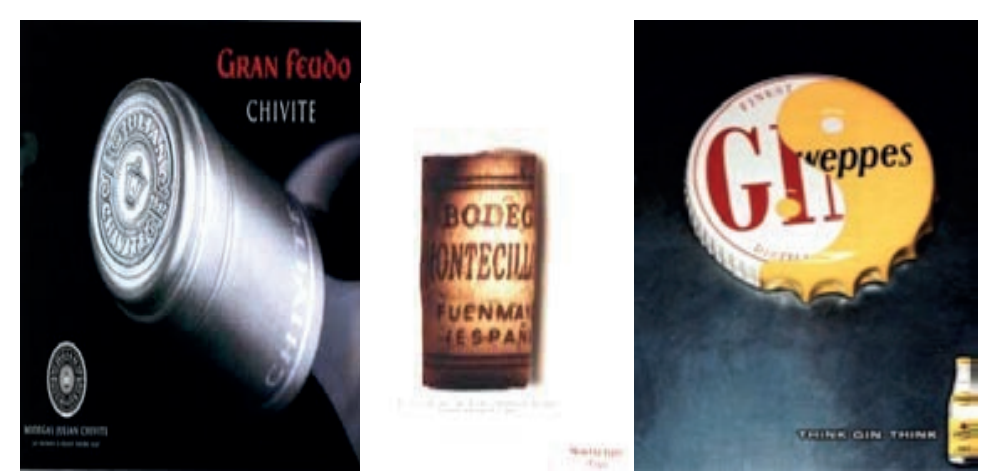

Figura 1. Ejemplos de metonimias de identidad

En todas y cada una de las metonimias de identidad encontradas, la marca está claramente plasmada, bien de forma explícita, bien de forma implícita en el elemento metonimizado, normalmente dispuesto de forma hiperbólica. El proceso 
metonímico proporciona al sujeto receptor una pista ineludible para establecer la reconstrucción total de la marca.

La participación del sujeto en este proceso es imprescindible. Sin la reconstrucción total del producto se perdería el significado y con ello la persuasión. No todas las partes de la botella son idóneas para sustituir parcialmente el producto, las sustituciones que en este trabajo se han encontrado se limitan básicamente al tapón del producto, bien sea en forma de chapa o de corcho (Chivite, Montecillo) y a la etiqueta. No es por casualidad, ambos elementos constituyen los componentes más distintivos del producto.

La representación del tapón no suele ser una representación real, adquiere tintes de metáfora, hipérbole, dispuestas de forma artística. Así, la función de la metonimia de identidad no es una mera representación del producto, sino que constituye un nuevo espacio en la construcción de la estrategia creativa y con ello, una nueva oportunidad para persuasión. En ocasiones, es corriente encontrar que el elemento seleccionado para presentar al producto es metaforizado o está sometido a un doble proceso metonímico.

En el caso del anuncio de Schweppes nos encontramos con una chapa dividida en dos partes simulando el Ying y el Yang que se entremezclan armoniosamente. La representación es una composición en la que se establece una metáfora entre ambos productos representados en la chapa. Es un juego en el que se busca vender la perfecta simbiosis de ambos productos. Parte de cada producto está representado en esta chapa de forma creativa y divertida. Permite así una imagen que irradia originalidad y que supone la fuerza de la estrategia creativa y comunicativa.

La segunda de las metonimias de identidad más común en esta categoría es la representación del producto mediante su etiqueta y el todo la marca. Este tipo de práctica no sólo es una parte más de la estrategia creativa o comunicativa, sino que en ocasiones es el sello distintivo de la comunicación publicitaria.
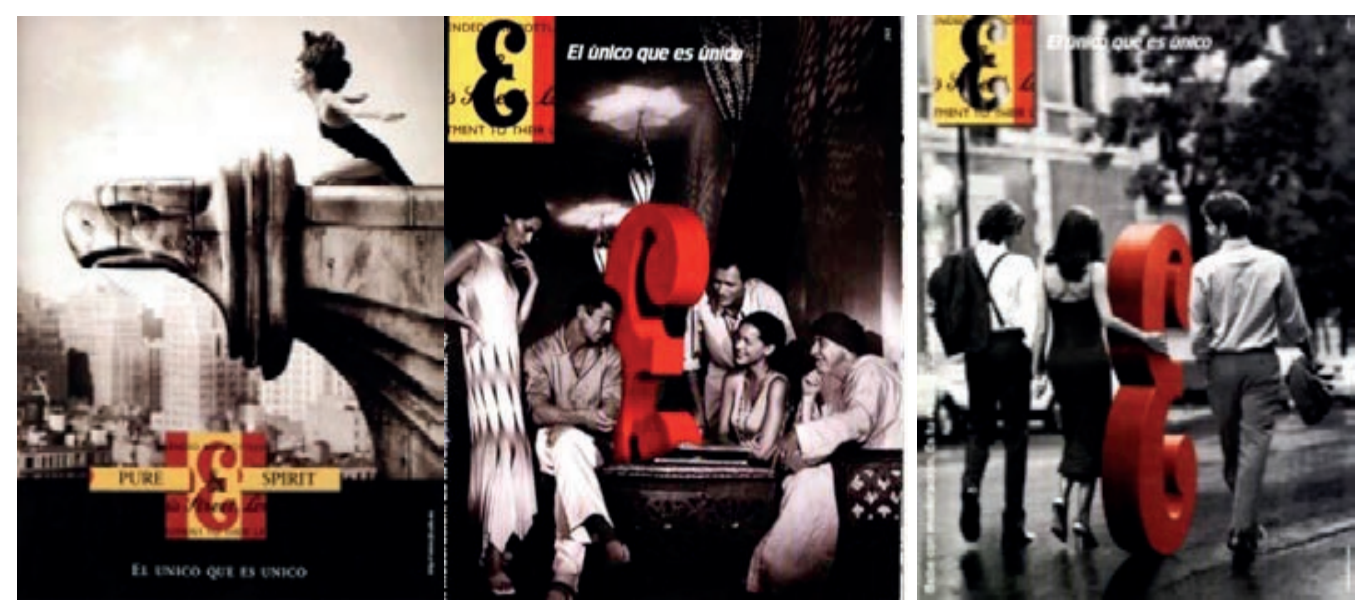

Figura 2. Ejemplos de metonimias como representación de la marca de productos. 
El proceso metonímico es posible gracias a un aprendizaje previo de marca. Todos estamos expuestos a un aprendizaje visual de logotipos, establecemos sin darnos cuenta asociaciones entre marcas y colores, sonidos, deportes... Construimos nuevos esquemas cognitivos o añadimos información a los ya existentes. Este aprendizaje es el que permite a los creativos diseñar campañas partiendo de etiquetas (Beefeater, Estola, Cardenalendoza, Cacique...).

En sus anuncios en blanco y negro resalta la representación de parte de la etiqueta de la marca con sus colores identificativos: el rojo y el amarillo. En la parte seleccionada de la etiqueta no se encuentran las letras distintivas "J", "B", que son las que dan nombre al producto, sino que se ha realizado una escisión en la parte central, dando como resultado una pequeña fracción en la que sólo aparece el símbolo "\&", que ocupa el lugar central en la etiqueta. A pesar de ser tan sólo una pequeña

fracción, el sujeto es capaz de reconocer la marca, su origen semántico marcará claras diferencias que permitan su reconocimiento. En los anuncios se establece un juego de significados entre el elemento " $\&$ " de la etiqueta y una serie de escenas que conforman el mensaje. ("Pure \& Memory", "Pure \& Dream", "Pure \& Passion”).

Las características de este tipo de productos, ya definidas con anterioridad, obligan al creativo a establecer atributos mediante la asociación con elementos totalmente ajenos a éste, transfiriendo una personalidad al producto que permite percibirle desde un ángulo totalmente distinto.

Este tipo de representación incita al sujeto receptor a considerar el producto desde la imagen de marca. El producto en sí, sus atributos físicos, a efectos prácticos poco nos importa, lo que realmente se está vendiendo es una idea, una forma de pensar y de vivir. La ausencia del producto ayuda al creativo a formar este tipo de concepto. El sujeto no alterna con el producto, alterna con una ideología. La personificación es tan extrema, que en la última campaña realizada por la marca J \& B, se llega a convertir el símbolo "\&" en uno más formando parte de una animosa conversación o convirtiéndose en un acompañante ideal de salidas nocturnas.

La sustitución de amigos, novios, por un elemento representativo del producto, nos hace que sintamos que el producto forma parte de nosotros, "es uno más" capaz de hacernos vivir los mejores momentos y estimular nuestra necesidad de intercambio social, de tal forma que J \& B, se convierte en un héroe de relación social, al que los sujetos receptores desean imitar.

Imaginemos este tipo de anuncios sin el proceso metonímico. Nos encontraríamos con un grupo de amigos abrazados a una botella o charlando con ella, la situación sería totalmente opuesta, las connotaciones que este tipo de escenas pudieran provocar en el sujeto receptor serían contrarias a las deseadas: la imagen de sujetos embriagados indeseables y lamentables, cuya situación tiene origen en el consumo de la bebida alcohólica. Es precisamente este tipo de connotaciones las que la marca quiere evitar. 
Gracias a la sustitución de la botella y a su personificación, nos resulta más fácil dar forma a la marca y al acto de beber, considerándolo como un hecho social en el que es imprescindible consumir J \& B. La estrategia comunicativa parte pues de un proceso metonímico que marca las pautas para el desarrollo de la estrategia creativa, no sólo de un anuncio, sino de toda una campaña de publicidad, utilizando la retórica como concepto paraguas a desarrollar en distintas campaña

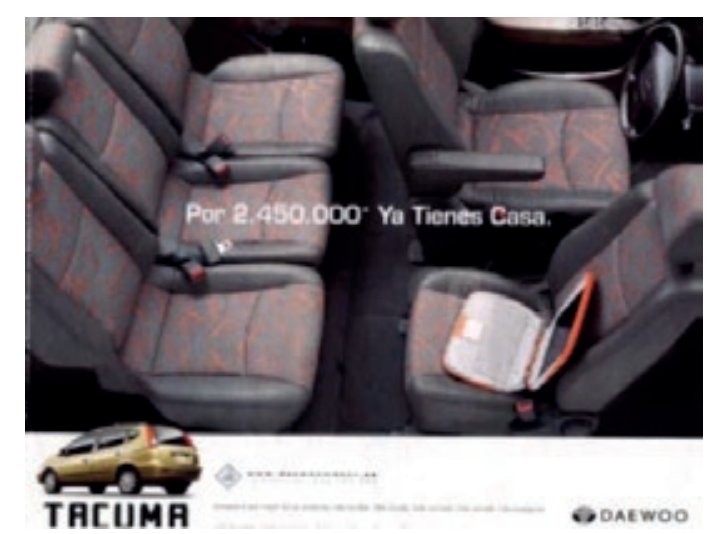

Figura 3. Ejemplos de metonimias, categoría automóvil.

En el caso de la categoría de automóvil, la referencia suele variar respecto a la categoría de bebidas puesto que en este caso la metáfora de identidad suele utilizarse para resaltar algunas de las ventajas físicas del producto.

Las metonimias de identidad de esta categoría, son principalmente elaboradas a partir de una pieza clave del vehículo. Esta pieza clave varía en función de las ventajas que el creativo quiera resaltar en el anuncio: un volante, un faro, la parte delantera del vehículo, el interior... Este elemento no es elegido al azar, se trata de una elección estratégica ligada a los objetivos comunicacionales. En el anuncio de la marca Daewoo Tacuma, podemos observar el interior del coche casi en su totalidad, mostrándonos una de las ventajas de este producto: la movilidad del asiento delantero del copiloto. Este recurso es muy común en los vehículos conocidos como "monovolumen" cuyo valor más codiciado es la capacidad y movilidad de los asientos. El comprador de este tipo de coches desea conocer el interior más que su estética o su potencia. Por lo tanto, el coche es presentado no en la totalidad sino parcialmente, mostrando estas ventajas y creando un elemento distintivo frente a su competencia.

Se ha detectado en esta investigación una perfecta comunión entre metáfora y metonimia. La metáfora utiliza la metonimia para poder establecer el nexo entre el producto y el significado. Podemos verlo en el caso del anuncio Lancia Y. Los faros del vehículo son objeto de un proceso metonímico, éstos son los únicos elementos que representan al coche, la disposición estética de ellos también suponen un proceso metafórico, central en la creación del significado.

Así, la metáfora parte de un proceso metonímico que permite presentarnos al producto de una forma nueva y original y sirve de nexo entre el nuevo significado y el 
producto promocionado.

Como vemos en los ejemplos mostrados, las metonimias textuales no son muy comunes en esta categoría, el elemento textual trata de paliar las carencias de información, es decir, nos aporta detalles del producto que se omiten en la parte iconográfica, elementos que por sus características muestran una gran complejidad a la hora de encontrar una representación icónica. Sí encuentran un lugar privilegiado en este tipo de anuncios los recursos de amplificación que actúan en perfecta simbiosis con los tropos. Es muy común encontrarnos con ambos recursos en el mismo anuncio, la amplificación trata de paliar la falta de información que puede resultar de la supresión derivada de la metonimia, proporcionando al receptor nueva información que ayude a reconstruir la totalidad del producto.

El sector automóvil junto con el de los productos de cosmética, presentan una mayor necesidad de información. Por su alta implicación, el sujeto necesita buscar información acerca de atributos físicos. La metonimia produce una simplificación que no termina de cubrir las necesidades del receptor y por ello, se hace necesario la inclusión de nuevos elementos retóricos, primordialmente el elemento por excelencia expositivo: el recurso de amplificación.

Así lo demuestran los datos obtenidos del análisis de los anuncios. En la categoría de automóviles y de perfumería droguería, la amplificación juega un papel de complementariedad. De un total de 188 anuncios analizados de la categoría de automóviles, 78 utilizan al menos un proceso metonímico. De estos 78 anuncios, 70 utilizan como recurso secundario la amplificación. Es decir, un 88\% de los anuncios analizados que contenían al menos una metonimia, utilizan como recurso secundario la amplificación.

Datos muy similares encontramos en la categoría de perfumería droguería. De un total de 302 anuncios, 123 utilizan al menos un proceso metonímico y de ellos un 77\% utilizan el recurso de amplificación como recurso secundario o primario, porcentaje menor que en el caso de la categoría de automóviles (88\%). La explicación de esta diferencia puede hallarse en la distinción dentro de la misma categoría de dos grupos de productos: perfumes y colonias de un lado, y cosmético de cuidado de la piel de otro: los perfumes se asemejan más a la publicitación de bebidas o textil y estos productos se encontrarían entre aquellos cuyos atributos son principalmente elaborados de forma artificial, en ellos la implicación es baja, y la aparición en el receptor de la necesidad de información es prácticamente nula. Por lo tanto, no es necesario cubrir las lagunas informativas que la metonimia puede ocasionar.

En estas dos categorías, la categoría de confección textil y la de bebidas, el porcentaje que representa la relación entre metonimia y amplificación en el grupo de moda es un $30 \%$, y un $33 \%$ en el de la bebida. 


\subsection{Metonimia de referencia espacio - temporal}

Se trata de una metonimia cuyo principal objetivo es generar significados mediante la utilización de esquemas cognitivos asociados con coordenadas espacio - temporales.

La metonimia referencial es construida a partir de un elemento capaz de desempeñar la función deíctica de la publicidad: referenciar lugar y tiempo, y asumir el acto material de la presentación.

Para ello, se elige un fragmento del esquema cognitivo capaz de representar un concepto abstracto o un objeto concreto para representar un concepto concreto. Los elementos seleccionados suelen formar parte de patrones establecidos y aceptados por la sociedad con fuertes cargas connotativas.

Para representar el campo semántico de un país acudimos a elementos creados por consenso como las banderas. Se trata pues, de esquemas popularizados y generalizados en la sociedad. Ante este tipo de proceso metonímico, el sujeto receptor utiliza un medio de evaluación simple para establecer el significado del mensaje, su análisis es automático. El receptor no se implica en generar argumentos o rebatirlos, simplemente se limita a realizar un análisis basado en un juicio popular, de tal modo que la metonimia, usualmente, actúa como pauta simple en el proceso de persuasión, generando actitudes relativamente temporales e incluso, y en algunas ocasiones, abriendo paso a la persuasión por ruta central.

El anuncio de vinos Conde de Valdemar está compuesto por tres elementos: una botella de vino, unos palos y una pelota de golf, estos últimos utilizados para establecer tanto el sentido del anuncio como los atributos y características del producto. Al sujeto receptor se le proporciona un pequeño fragmento de un dominio: los palos y las pelotas de golf, y a partir de este pequeño fragmento reconstruye toda una realidad. Son elementos fácilmente reconocibles por lo que el sujeto está capacitado para la reconstrucción del contexto y del significado del mensaje. El texto del mensaje reza: "No recuerdo el día exacto en el que gané el torneo, pero recuerdo con claridad el vino que bebimos para celebrarlo". Situamos pues, la botella de vino dentro de un ágape de celebración de un torneo de golf (Ver Figura 4), es de este modo como se establece la relación racional entre golf y vino Conde Valdemar. La relación emocional parte del campo semántico de este deporte, que es transferida al producto. El proceso metonímico lleva al sujeto receptor a localizar y contextualizar la marca de vinos dentro de un ambiente selecto y exclusivo, propio de este deporte y asociado con ganadores, como el protagonista de nuestra historia. 


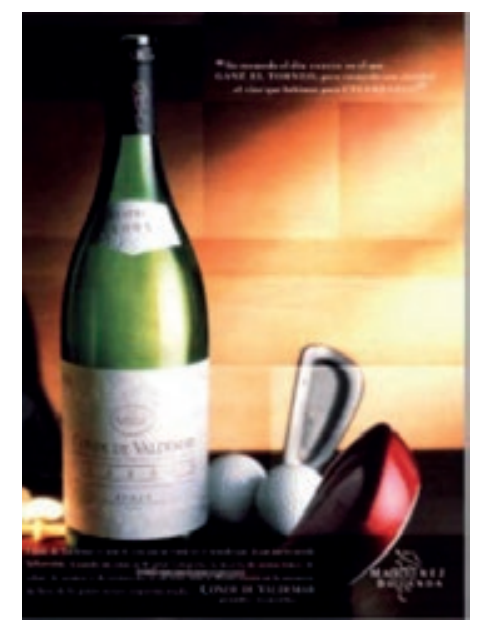

Figura 4. Ejemplos de metonimias, categoría bebida

En el sector de bebidas es ésta una práctica muy habitual, puesto que es necesario establecer conexiones entre distintos campos semánticos que les permitan apoderarse de nuevos atributos y cualidades hasta entonces ajenos al producto o a la marca. En los inicios de la comunicación publicitaria, los atributos eran inherentes a las cualidades físico/químicas, hoy en día es la retórica la que se encarga de resaltar y crear los atributos del producto.

En la primera etapa de la publicidad, aunque esto no permita una generalización absoluta, los valores añadidos, asociados al producto, tendían a ser explicativos de sus cualidades físico - químicas. La publicidad moderna se aleja, cada día más, de estas asociaciones informativas, para codificar sus mensajes de acuerdo con asociaciones que hacen referencia al sistema de valores de la cultura comercial burguesa ${ }^{12}$.

En las cuatro categorías nos encontramos con la construcción de significados gracias a un proceso metonímico referencial, capaz de generar la inferencia de valores que propician la creación de afecto en el receptor.

Este proceso tiene lugar en el anuncio de Ron Bacardí, donde las coordenadas espaciales son básicas a la hora de establecer su sentido y de crear connotaciones. Una botella de Bacardí junto a una de Fanta, unas estrellas de mar e inmerso en una blanca y fina arena de playa. Estos elementos nos revelan un paisaje paradisíaco, capaz por sí sólo de generar toda una batería de connotaciones e inferencias acerca del consumo de este producto.

La asociación con este tipo de elemento radica en las características que atribuimos a los lugares paradisíacos: la sensualidad, el erotismo, la tranquilidad, la belleza, la intensidad, junto con el valor de la elaboración artesanal, y la calidad de su principal ingrediente; la caña de azúcar.

12 Moragas Spa, M. Semiótica y Comunicación de Masas, Editorial Península. Barcelona 1976 
El proceso metonímico parte del aprendizaje popular y de las destrezas cognitivas adquiridas con los años y conduce a la búsqueda del significado mediante la activación de procesos automáticos que llevan a la construcción de una nueva información.

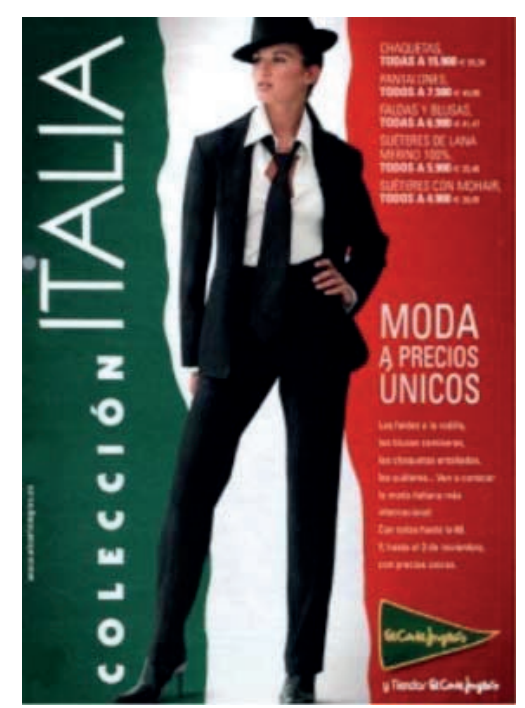

Figura 5. Ejemplos de metonimias, categoría textiles

En su reconstrucción, no sólo es importante reconocer el espacio físico que se describe, sino la totalidad de su esquema semántico, que es realmente el que proporcionan al mensaje un sentido, que a su vez no permite presentar la ventaja del producto con el fin de persuadir al sujeto. Es decir, el receptor no se frena al reconocer por ejemplo, las islas caribeñas, sino que además, busca entre sus conocimientos, atributos capaces de describir este concepto transformándolo en significado.

En la categoría bebidas, la creación de atributos se convierte muy a menudo en un proceso de origen artificial, la intangibilidad propia del producto es una de las principales causas, pero además, el origen de las necesidades que satisfacen este producto constituye uno de los elementos esenciales a la hora de seleccionar los recursos retóricos.

Las metonimias de referencia espacio temporal en la categoría de automóviles son principalmente de dos tipos: la que busca la simbiosis entre el campo semántico de un país y el automóvil, y aquellas que proponen la relación entre el automóvil y el tipo de escenario según funcionalidad.

La metodología y la investigación llevada a cabo por los distintos fabricantes de automóviles, han marcado tradicionalmente notables diferencias entre ellos. La asociación país - fabricante está patente en nuestros esquemas: los automóviles ingleses son elegantes, los alemanes potentes, los japoneses dotados de alta tecnología, etc., de tal forma que con sólo asociar el producto a uno de estos países logramos dotarles de unas determinadas características, lo que supone una gran 
ventaja para el creativo, puesto que parte de un camino ya andado, asumido y aceptado por el sujeto receptor, permitiendo una redundancia significativa que parte de un esfuerzo cognitivo mínimo, no necesitando convencer ni disuadir acerca de determinadas características del vehículo, sólo de su relación con el país.

Es el caso de la marca Mazda (Ver Figura 6), el elemento metonímico se construye a través de una de las partes de la bandera de Japón: el círculo rojo. Las inferencias en este caso están asociadas a la tecnología, no se vende belleza ni se promociona el precio, sino que se destaca la capacidad tecnológica del vehículo, y esta ventaja es la que proponen como atributo distintivo frente a su competencia.

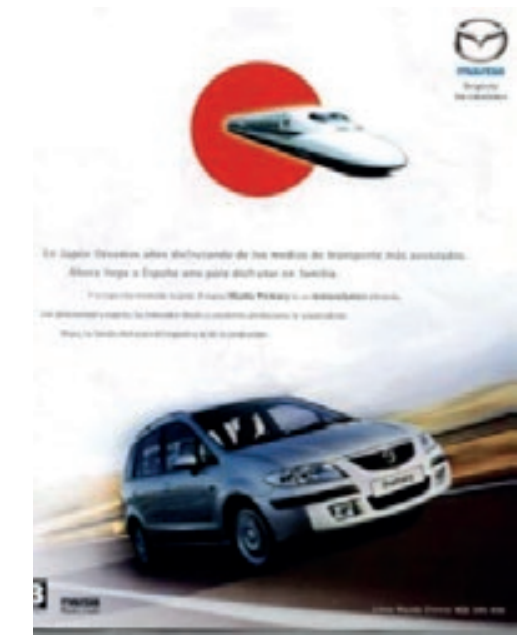

Figura 6. Ejemplos de metonimias el caso de la marca Mazda

La segunda opción, más habitual asociación con distintos espacios en en esta categoría, es la base a la funcionalidad promocionada: la montaña, la selva, la ciudad. Los mensajes publicitarios de un vehículo todo terreno nada tienen que ver con los mensajes que se utilizan para promocionar un turismo de gama alta o un utilitario propio de la ciudad. Las ventajas de este tipo de vehículos se crean partiendo de elementos espaciales que permiten la reconstrucción del significado en base tanto a la funcionalidad del producto como a la descripción de su público objetivo o a la ventaja publicitaria.

La asociación entre este tipo de escenarios y el vehículo promocionado no sólo nos indica sus atributos físicos, sino que además describe un tipo de público objetivo que disfruta con el riesgo, con la aventura. Es una clara invitación a la superación de barreras, a llegar a aquellos lugares donde nadie ha llegado, a correr aquellas aventuras deseadas. En definitiva, la metonimia supone el elemento esencial en la construcción de la ventaja del producto y la estrategia comunicacional.

En relación con el segmento textil, también es patente la apropiación semántica provocada por la simbiosis países - productos, representados éstos mediante procesos metonímicos. 
Los prejuicios populares son muy utilizados para promocionar las distintas colecciones. Una prenda asociada a una bandera francesa o italiana cobra rápidamente un nuevo valor. El sujeto receptor, en su intento por la búsqueda de significado, acude a sus conocimientos y trata de contextualizarlos buscando relaciones entre el país representado por la bandera

y la moda. Rápidamente llegará a la conclusión de que la colección que tiene ante sí es una gran colección, llena de glamour y elegancia (El Corte Inglés). Cualquier elemento distintivo del país es susceptible de ser metonimizado, aunque el más común es su bandera.

La categoría de perfumería droguería es muy similar en este aspecto a la categoría de confección textil (Ver Figura 7). La promoción de estos artículos utiliza las metonimias de referencia espacio temporal para aportar a sus productos atributos como la calidad y el prestigio. Así oscilan entre el frescor de la naturaleza, para las colonias, y los lugares exóticos sensuales y / o románticos para los perfumes.

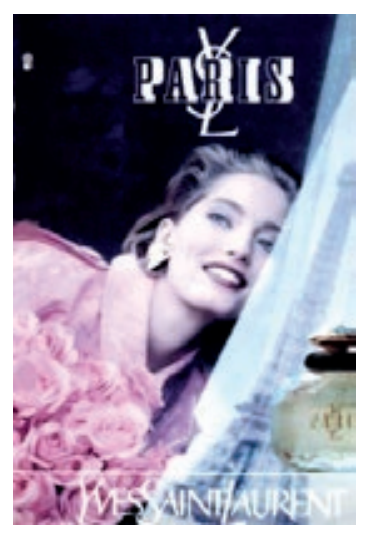

Figura 7. Ejemplos de metonimias, categoría: perfumería

Los anuncios de las colonias utilizan entornos asociados con la naturaleza: fuentes, manantiales, arroyos, lugares donde el sujeto sienta el frescor que irradia el agua, estableciendo un paralelismo entre este frescor y el que proporciona el producto. Los perfumes optan por la elegancia y la sensualidad con toques románticos. Una mujer portando flores y la imagen de la Torre Eiffel en segundo plano, son elementos suficientes para contar una bella historia de amor rodeada de glamour. (Yves Saint Laurent).

El producto se impregna del significado de todos aquellos elementos que participan en el anuncio, de tal forma que el perfume se convierte en el perfume del amor, del romanticismo, de la elegancia y la pasión.

Cada una de las categorías de producto utiliza las metonimias de referencia atendiendo a su particularidad, pero siempre persiguiendo los mismos objetivos: la transferencia de atributos de una entidad espacio temporal a un concepto, transferencia que otorga al mensaje un nuevo significado y un nuevo sentido, capaz de despertar en el sujeto necesidades imprescindibles en el proceso de persuasión. 
Es usual que trabajen como elementos simples, puesto que su construcción e interpretación no dan lugar, de forma general, a la elaboración de pensamientos

\subsection{Metonimia de construcción}

Son aquellas metonimias cuya principal función es la de contribuir de forma parcial o total con el significado del mensaje. No se trata de metonimias dispuestas para cubrir la función deíctica, ni metonimias construidas a partir de entidades del producto. La metonimia de construcción no representa al producto, sino que forma parte de un conjunto de elementos destinados a crear significados, función distinta a la acontecida en la metonimia de referencia espacio temporal.

Este tipo de metonimias suponen, para la categoría de perfumería droguería, un sin fin de posibilidades a la hora de propiciar connotaciones e inferencias. Actúan en algunas ocasiones de forma similar a la metáfora, contribuyendo con la creación de significados, aportando al producto una entidad y un sentido distintivo. La mayor parte de las metonimias establecidas en esta categoría son del tipo "causa por efecto" y "materia por el objeto".

Los anunciantes de cremas de cuidado facial necesitan transmitir el efecto de sus tratamientos. Recordemos por ejemplo, la estrategia seguida por gran parte de los creativos para promocionar productos adelgazantes: primero se presenta al protagonista con unos kilos de más, y en el siguiente plano o secuencia, el mismo protagonista se encuentra liberado de todos esos kilos. El esquema seguido es muy sencillo: "un antes" y "un después". En la publicidad gráfica, la opción más común es la de mostrar sólo una de estas etapas, la etapa de "después", es decir, el efecto y no la causa.

Esta peculiaridad obliga a los creativos a encontrar elementos que puedan trasmitir el final de proceso, una de las estrategias más comunes para lograr estos objetivos es la simbiosis entre metáforas y metonimias.

Estos procesos son capaces de transmitir al sujeto receptor atributos y cualidades del producto que favorecen la aparición de sensaciones placenteras. Es el caso de la utilización del elemento "agua" para promocionar cremas hidratantes. El efecto de hidratar la piel se corresponde con la grata sensación de una piel fresca, frescor difícil de trasmitir mediante un medio impreso, por ello se utiliza el elemento que por excelencia es considerado más refrescante: el agua, mediante una entidad, una gota de agua.

En este caso, el deslizamiento se produce en términos efecto causa, el objetivo real de este proceso metonímico es que el receptor conecte con una determinada sensación y la asocie con la utilización del producto, mostrándonos por un lado, el efecto (el frescor), y por otro la causa (el producto). La búsqueda del efecto se convierte en la publicidad de cosméticos en una constante que marca una estética. Tomemos como 
ejemplo los anuncios de barras de labios, muy similares en su esquema estructural, en los que podemos encontrarnos una línea común: la fotografía de la parte inferior del rostro de una mujer, en la que destaca el color y el brillo de sus labios. Se establece un doble proceso metonímico, basado en una sustitución parcial y otra total.

La sustitución parcial es la que corresponde a la representación de la mujer, de la que tan sólo conocemos una pequeña parte de su rostro. La segunda de las sustituciones es total, el producto es sustituido por su efecto, el aspecto de los labios, y esta sustitución supone la desaparición del producto, que es representado por su capacidad para dar brillo, hidratar, embellecer..., es decir, por su efecto.

La metonimia de construcción además de trasmitir sensaciones, favorece un acercamiento entre la marca y el sujeto receptor gracias la utilización de procesos del tipo "el todo por la parte" o "la parte por el todo": "el iluminador ideal para todas las mujeres". Esto permite por un lado, el acercamiento entre marca y sujeto, gracias a la utilización de la marca desde un concepto unipersonal y no desde el concepto semántico al que estamos más acostumbrados.

De otro lado, permite la definición del producto partiendo de una de sus características: "el mate que cuida tus labios", estrategia muy útil para destacar la característica distintiva del producto.

Este procedimiento es común a las cuatro categorías. En la categoría de automóviles, la mayor parte de estos procesos persiguen la construcción de la personificación del producto mediante el deslizamiento de significado. La personificación de los automóviles es un factor primordial: es necesario vender formas de vivir, de actuar, de comportarse, que no sólo procuran la apelación de las necesidades, sino que además establece las barreras distintivas entre un modelo y otro.

Si nos encontramos a un niño haciendo sus necesidades en un casco militar heredado de uno de sus más notables antepasados (Renault Scenic), podemos interpretar que se trata de un personaje rebelde, atrevido, valiente, capaz de enfrentarse a las tradiciones más arraigadas. El elemento clave para llegar a reconstruir este significado, deviene de un proceso metonímico, en el que la tradición simbolizada por el aspecto militar de la familia, es a su vez representada por un casco militar sobre el que un pequeñín está haciendo sus necesidades. Este acto simboliza el cambio, la transgresión, una nueva forma de vivir y entender la vida. Estos son algunos de los rasgos que el creativo quiere que veamos en el producto: un coche nuevo, transgresor, lleno de vitalidad y rebeldía y que por descontado, está pensado para jóvenes que se identifiquen con esta nueva forma de ver la vida.

El proceso metafórico que induce a esta interpretación parte de una predicación metonímica. Ambos procesos, el metafórico y el metonímico, actúan conjuntamente de forma dependiente siendo ambos los responsables de la creación de significados. 


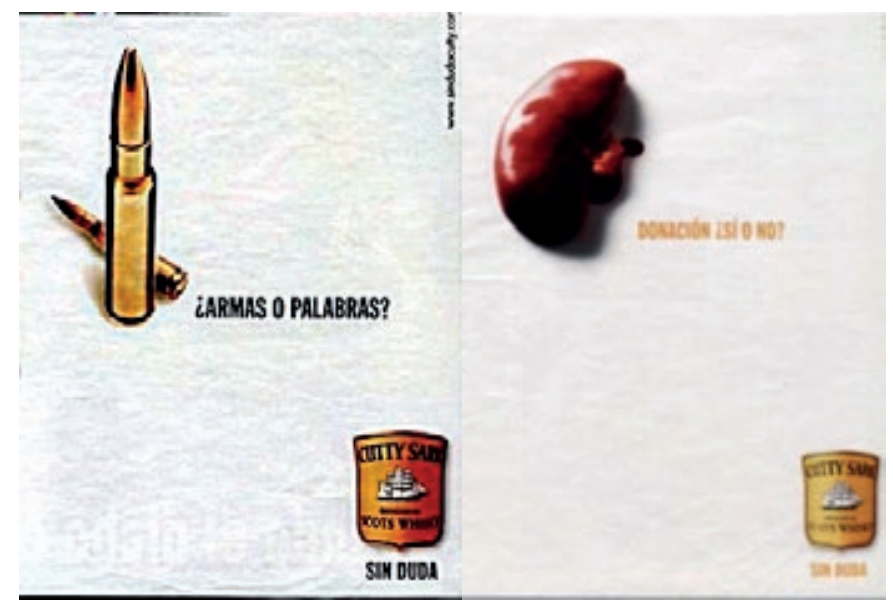

Figura 8. Ejemplos de metonimias

En la categoría confección textil se encuentran poco representadas las metonimias de construcción, los ejemplos se limitan a la exposición en un segundo plano de entidades que contribuyen con la descripción artificial del producto. Unos guantes de boxeo que reflejan un carácter combativo, una cruz y una virgen dispuestos de forma trasgresora... casi siempre son elementos que ocupan un segundo plano y aportan algún dato importante pero no resolutorio acerca del producto.

En el análisis de la categoría de bebidas, son muy limitados los ejemplos que encontramos de este tipo de metonimia, este producto elige principalmente la metáfora y las metonimias de producto y de ubicación, tanto para transmitir valores y atributos, como para contribuir con la creación de significados.

La campaña lanzada en el año 2000 por Cutty Sark apoya su estrategia creativa en un proceso de metonimia de construcción mediante entidades unidas a conceptos que ocasionan debate en la sociedad, tales como la entidad del riñón para representar a los trasplantes, las balas para representar las armas..., el creativo busca por un lado, que el sujeto de forma rápida identifique la entidad con el concepto y establezca un debate interior acerca del tema, y por otro, la aparición conjunta de la bebida y la entidad totalmente ajena a la marca e intrusa en el contexto, suscita en el receptor curiosidad que satisface con la búsqueda de más información.

\section{CONCLUSIONES}

Hemos logrado de esta forma cubrir las primeras exigencias de la persuasión, el sujeto ha entrado en contacto con nuestro mensaje, que descifra tras descubrir la metáfora que el creativo plantea mediante una erotema. El mensaje es sencillo, puedes establecer debates entre temas cargados de controversia, pero no consientas que se instalen dudas acerca de la marca de whisky que debes consumir.

La metonimia es un elemento más en la construcción de este significado, y es utilizado para representar, siguiendo los principios de economía expresiva, todo un concepto 
cargado de polémica, y además activar en el receptor las alertas de atención. Las características más destacadas de este tipo de metonimia son su capacidad para el trabajo en equipo.

Tratamos con una metonimia de apoyo que aporta información necesaria de forma escueta para la construcción de significados y atributos, pero que por sí sola es incapaz de llevar a cabo este tipo de labor. El grado de retórica más representativo de los anuncios donde se han encontrado este tipo de metonimia, es el grado 4, es decir, existe una representación bastante significativa del resto de los grupos de recursos, de hecho no existe ningún anuncio donde la metonimia de construcción constituya un nivel 1 de retórica, esta circunstancia es debida a la escasa fuerza que demuestran tener este tipo de metonimias, que a pesar de ser muy utilizadas en la totalidad de las categorías, deben ir siempre acompañadas de otros recursos que contribuyan tanto en la creación de significados como en la construcción del contexto.

\section{REFERENCIAS}

Du marsais. (2004). Tratado de los tropos, (Trad. J. M. Aléa) Madrid: Aznar (Original en francés, 1730)

Eco, U. (1975). Tratado de Semiótica General. (Trad. C. Manzano) Editorial Lumen, Colección: Palabra en el Tiempo, Quinta Edición. pp. 130-131

Lakoff g. Y \& Johnson M.(2001) .Metáforas de la vida cotidiana. Madrid: Cátedra.

Spang K. (1984). Fundamentos de retórica (2ª ed). Pamplona: Eunsa

Moragas Spa, M. (1976). Semiótica y Comunicación de Masas. Barcelona:Editorial Península.

Bermejo J. (1999). De la promesa publicitaria a las necesidades emergentes del receptor. Revista Internacional de investigaciones publicitarias Pensar la Publicidad (2) 9-30

Bermejo J. (2007). Teoría del Hexágono de Apelaciones Publicitarias y Necesidades Emergentes. Revista Internacional de investigaciones publicitarias Pensar la Publicidad, (1), 99-131

\section{Marian Núñez Cansado}

Licenciada en Ciencias de la Información, Universidad Complutense de Madrid (1996) Doctora en Ciencias de la Comunicación y Sociología, Universidad Complutense de Madrid (2005). Trabajo actual: Crandom College, profesor asociado, ha impartido las siguientes asignaturas: Investigación de mercados, Creatividad, Teoría de la Imagen, Ética y Deontología de la Publicidad, Modelos Análisis Publicitarios, Creatividad Publicitaria II, entre otras. Ha participado en varios proyectos de investigación relacionados con la publicidad. 


\section{APÉNDICE}

Apéndice 1: cuadro selección de revistas

\begin{tabular}{|c|c|c|}
\hline Revista & $\mathrm{N}^{\mathrm{o}}$ anuncios & Fórmula: $\mathrm{T} \times \mathrm{N} \times \mathrm{P}$ \\
\hline 1. Anuario $\mathrm{ABC}$ & 30 & $12 \times 30 \times 1=360$ \\
\hline 2. Autopista & 76 & $12 \times 76 \times 52=47.424$ \\
\hline 3. Biba & 40 & $12 \times 40 \times 12=5.760$ \\
\hline 4. Blanco y Negro & 36 & $12 \times 36 \times 52=22.464$ \\
\hline 5. Canal + & 20 & $12 \times 20 \times 12=2.880$ \\
\hline 6. Casa Diez & 19 & $12 \times 19 \times 12=2.736$ \\
\hline 7. Coche actual & 84 & $12 \times 84 \times 52=52.416$ \\
\hline 8. Cosmopolitan & 73 & $12 \times 73 \times 12=10.512$ \\
\hline 9. Dietas & 38 & $12 \times 38 \times 12=5.472$ \\
\hline 10. Diez Minutos & 32 & $12 \times 32 \times 52=19.968$ \\
\hline 11. Dunia & 40 & $12 \times 40 \times 12=5.760$ \\
\hline 12. $\mathrm{ECU}$ & 32 & $12 \times 32 \times 2=768$ \\
\hline 13. El Cultural & 29 & $12 \times 21 \times 12=3.024$ \\
\hline 14. El Dominical & 28 & $12 \times 28 \times 52=17.472$ \\
\hline 15. El Duende de Madrid & 38 & $12 \times 38 \times 12=5.472$ \\
\hline 16. El Jueves & 36 & $12 \times 36 \times 52=22.464$ \\
\hline 17. El País Semanal & 37 & $12 \times 37 \times 52=23.088$ \\
\hline 18. El Semanal & 37 & $12 \times 37 \times 52=23.088$ \\
\hline 19. $\quad$ Elle & 108 & $12 \times 108 \times 12=15.552$ \\
\hline 20. Estrenos & 60 & $12 \times 60 \times 12=8.640$ \\
\hline 21. Hola & 39 & $12 \times 39 \times 52=24.336$ \\
\hline 22. Interviú & 62 & $12 \times 62 \times 12=8.929$ \\
\hline 23. Kilómetro Mapfre & 30 & $12 \times 30 \times 2=720$ \\
\hline 24. La Guía de mi bebe & 80 & $12 \times 80 \times 1=960$ \\
\hline 25. La Revistas & 29 & $12 \times 29 \times 52=18.096$ \\
\hline 26. Lecturas & 20 & $12 \times 20 \times 52=12.480$ \\
\hline
\end{tabular}




\begin{tabular}{|ll|l|l|}
\hline 27. & Magazine & 20 & $12 \times 20 \times 52=12.480$ \\
\hline 28. & Marie Claire & 97 & $12 \times 97 \times 12=13.968$ \\
\hline 29. & Mi Casa & 38 & $12 \times 38 \times 12=5.472$ \\
\hline 30. & Muy Interesante & 76 & $12 \times 76 \times 12=10.944$ \\
\hline 31. & Mía & 38 & $12 \times 38 \times 52=23.712$ \\
\hline 32. & Oro & 30 & $12 \times 30 \times 12=4.320$ \\
\hline 33. & Mujer de Hoy & 11 & $12 \times 11 \times 52=6.864$ \\
\hline 34. & Pronto & 37 & $12 \times 37 \times 52=23.088$ \\
\hline 35. & Pryma & 39 & $12 \times 39 \times 52=24.336$ \\
\hline
\end{tabular}

